\title{
Effectiveness Testing of an Inverse Method for Balancing Nonlinear Rotordynamic Systems
}

DOI:

Effectiveness Testing of an Inverse Method for Balancing Nonlinear Rotordynamic Systems

\section{Document Version}

Accepted author manuscript

Link to publication record in Manchester Research Explorer

\section{Citation for published version (APA):}

Torres Cedillo, S. G., Al-Ghazal, G. G., Bonello, P., \& Cortés Pérez, J. (2018). Effectiveness Testing of an Inverse Method for Balancing Nonlinear Rotordynamic Systems. In Proceedings of ASME Turbo Expo 2018:

Turbomachinery Technical Conference and Exposition https://doi.org/Effectiveness Testing of an Inverse Method for Balancing Nonlinear Rotordynamic Systems

\section{Published in:}

Proceedings of ASME Turbo Expo 2018: Turbomachinery Technical Conference and Exposition

\section{Citing this paper}

Please note that where the full-text provided on Manchester Research Explorer is the Author Accepted Manuscript or Proof version this may differ from the final Published version. If citing, it is advised that you check and use the publisher's definitive version.

\section{General rights}

Copyright and moral rights for the publications made accessible in the Research Explorer are retained by the authors and/or other copyright owners and it is a condition of accessing publications that users recognise and abide by the legal requirements associated with these rights.

\section{Takedown policy}

If you believe that this document breaches copyright please refer to the University of Manchester's Takedown Procedures [http://man.ac.uk/04Y6Bo] or contact uml.scholarlycommunications@manchester.ac.uk providing relevant details, so we can investigate your claim.

\section{OPEN ACCESS}




\title{
EFFECTIVENESS TESTING OF AN INVERSE METHOD FOR BALANCING NONLINEAR ROTORDYNAMIC SYSTEMS
}

\author{
Sergio G. Torres Cedillo \\ Centro Tecnológico Aragón, FES Aragón, Universidad \\ Nacional Autónoma de México (UNAM), Av. Rancho Seco \\ s/n, Edo. de México, México. C.P. 57130. \\ Ghaith Ghanim Al-Ghazal \\ School of Mechanical, Aerospace and Civil Engineering, \\ University of Manchester. Manchester, UK
}

\author{
Philip Bonello \\ School of Mechanical, Aerospace and Civil Engineering, \\ University of Manchester. Manchester, UK \\ Jacinto Cortés Pérez \\ Centro Tecnológico Aragón, FES Aragón, Universidad \\ Nacional Autónoma de México (UNAM), Av. Rancho \\ Seco s/n, Edo. de México, México. C.P. 57130.
}

\begin{abstract}
Alberto Reyes Solis
Centro Tecnológico Aragón, FES Aragón, Universidad Nacional Autónoma de México (UNAM), Av. Rancho Seco s/n, Edo. de México, México. C.P. 57130.
\end{abstract}

\begin{abstract}
Modern aero-engine structures typically have at least two nested rotors mounted within a flexible casing via squeezefilm damper (SFD) bearings. The inaccessibility of the HP rotor under operational conditions motivates the use of a noninvasive inverse problem procedure for identifying the unbalance. Such an inverse problem requires prior knowledge of the structure and measurements of the vibrations at the casing. Recent work by the authors reported a non-invasive inverse method for the balancing of rotordynamic systems with nonlinear squeeze-film damper (SFD) bearings, which overcomes several limitations of earlier works. However, it was not applied to a common practical configuration wherein the HP rotor is mounted on the casing via just one weak linear connection (retainer spring), with the other connections being highly nonlinear SFDs. The analysis of the present paper considers such a system. It explores the influence of the condition number and how it is affected as the number of sensors and/or measurement speeds is increased. The results show that increasing the number of measurement speeds has a far more significant impact on the conditioning of the problem than increasing the number of sensors. The balancing effectiveness is reasonably good under practical noise level conditions, but significantly lower than obtained for the previously considered simpler configurations.
\end{abstract}

\section{INTRODUCTION}

The airline industry increasingly demands low levels of vibration transmitted to the aircraft's fuselage, in the interests of structural integrity and passenger comfort. This is even more so in the case of business travel jets, where the aircraft engine is directly mounted on the aircraft's fuselage or wings.
Over the years, the aircraft-engine design has been optimized to seek lightweight and flexible structures with very little inherent damping. The Squeeze-Film Damper (SFD) bearing provides a highly cost-effective means of introducing damping into such structures. The SFD is achieved by pumping oil into the annular clearance between the outer race of a rollingelement bearing and its housing (See Figure 1). Nonetheless, the flexible casing structure is highly sensitive to the vibration excitation emerging from the coaxial nested rotors, as illustrated in the twin-spool engine shown in Figure 1, where the (higher speed) high pressure (HP) rotor is nested inside the low pressure (LP) rotor. The unbalance estimation of these rotors is a main concern, especially since the vibrationdependent nonlinear forces from the SFD bearings may introduce undesirable phenomena into the structural response that are aggravated by increasing unbalance.

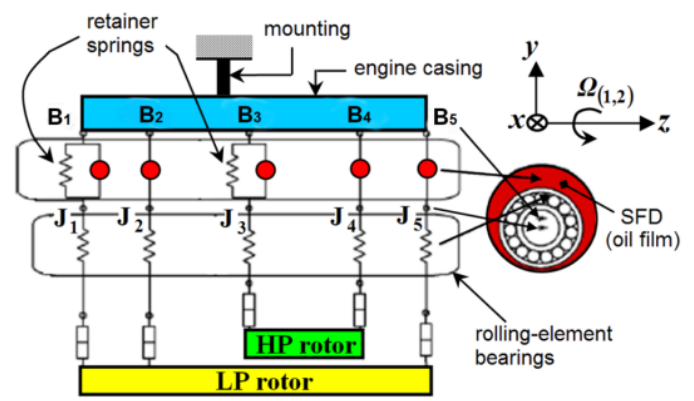

Figure 1: Schematic of a typical twin spool engine[1]

As stated in [1,2], traditional trim balancing methods [3-5] are typically applied for balancing the LP rotor. Such methods require the application of trial masses and several runs to be 
conducted. However, these methods cannot be used in those applications where the source of vibration (i.e. HP rotor) is not readily accessible under operational conditions as seen in Figure 1. This motivates the use of a non-invasive inverse problem procedure for balancing the HP rotor. This approach uses measurements of the vibrations at the casing and prior knowledge of the structure to identify the unbalance, thus enabling a "right first time" corrective (balancing) action.

Most previous research on such inverse problems employed a linearized approximation of the bearing model e.g. [6,7]. This can work well for journal bearing applications, as successfully validated in [7]. However, such linearized approximations are considered unsuitable for SFD bearings used in aero-engine applications, since these require the full nonlinear model $[1,2,8,9]$. Pioneering work of Dicken et al. [1] considered the solution of a non-invasive inverse problem for the balancing of rotordynamic systems with nonlinear SFD bearings, focusing on a simplified model of the HP rotor-casing system. However, this work had various limitations that were overcome by the method introduced by Torres-Cedillo and Bonello in [2] that had the following advantages relative to [1]:

- No restriction on the nonlinearity of the SFDs and the ability capability to accommodate realistic conditions in the SFD, i.e. does not require the highly idealised assumption of circular centred SFD orbits made in [1].

- Can be equally applicable to casing vibration that has nonsynchronous frequency components.

- Can be formulated in terms of the modal parameters of the linear part of the system, which is generic and is also not restricted by assumptions made in [1] like isotropy.

- Can include gyroscopic effects.

- No restriction on the number of SFD bearings.

The work in [2] proposed the Receptance Harmonic Balance Method (RHBM) as underpinning theory to generate the backward operator using vibration response at the engine casing. This method showed excellent balancing effectiveness when there is an adequately strong linear connection between the rotor and the casing, in addition to the nonlinear connections (i.e. the oil films of the SFD bearings). However, this preceding work [2] did not investigate the case when the squeeze-film damped rotor system contains only one weak linear connection between the rotor and casing. Therefore, the present study is devoted to determining the balancing effectiveness of the inverse technique when it is applied to such a rotordynamic configuration, which is used in many practical aero-engine designs (where the HP rotor is supported on the casing by a sprung SFD at one end and an unsprung SFD at the other end, as can be seen in Figure 1).

As in the previous work [2], the analysis presented in the present paper uses simulated data for the casing vibration that is corrupted by various levels of noise.

The remaining part of the paper is structured as follows. Section 2 presents the details of the rotordynamic system considered. In section 3 , the theory for the forward problem and the explicit inverse solution are set up. Section 4 describes the generation of simulated casing data. Section 5 presents and discusses the test cases.

\section{FLEXIBLE ROTOR/CASING SFD SYSTEM}

Figure 2 shows the flexible rotor/casing SFD system which is used on the current study. As in work of Dicken et al. [1], and the authors' previous works [2,9], the LP rotor is not included, since it is assumed to be balanced by traditional balancing methods as stated in $[1,2,8,9]$. In contrast to preceding works $[1,2,9]$, the HP rotor is supported on the casing by the two types of SFD bearings, one of them is a spring-supported SFD at the left-hand side and the other one is an unsupported SFD bearing at the right-hand side (see Figure 2). In the springsupported SFD the static load is totally supported by the retainer spring, which is in parallel with the SFD (oil annulus). This spring is considered a weak linear connection rotorcasing since its stiffness is typically low for vibration isolation purposes. It is also noted that, as is customary e.g. [1,2,9-14], the rolling element bearing that is surrounded by the SFD (oil film) is regarded as rigid relative to the oil film.

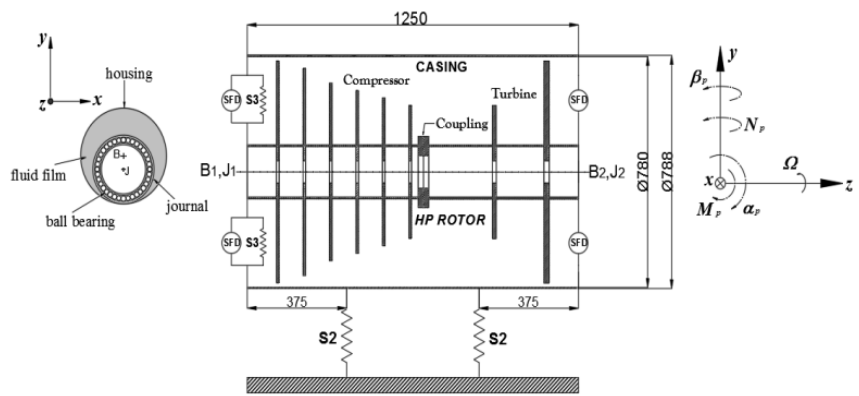

Figure 2: Flexible rotor/casing SFD system (dim. in mm).

As in [2,9],the current case study also considered the elastic mounting support S2 of the casing to be anisotropic (300 $\mathrm{MN} / \mathrm{m}, 600 \mathrm{MN} / \mathrm{m}$ in horizontal and vertical planes respectively). The retainer spring (S3) is isotropic and has stiffness of $30 \mathrm{MN} / \mathrm{m}$. Static offset at the SFD is considered. Anisotropy of the engine mountings and static eccentricity of SFD correspond to the real situation and can be accommodated by the present inverse balancing method, in contrast to [1].

\subsection{Modal parameters.}

As in the 'forward' solution methods (determination of vibration response from known unbalance) in $[2,9,13,14]$, the inverse method (determination of unbalance from known vibration response) employs the eigenforms and eigenfrequencies of the linear part of the system (see Figure 3) under non-rotating conditions, computed from a one-off eigenvalue analysis. The 'linear part' of the system is the system that results when the SFDs (oil films) are removed (i.e. replaced by gaps). In this study case, the linear part of the current HP rotor will therefore be "sprung-free". The modal parameters in each of horizontal and vertical planes were computed from the finite element (FE) model using NASTRAN [15], where beam elements were used for the rotor shaft and cylindrical casing and concentrated inertia elements 
("disks") for the compressor/turbine disks and couplings. The material and geometric properties were taken from $[1,2,9]$, to enable the calculations of their modal properties. Figure 3(a, b) shows the first six modes shapes (and their eigenfrequencies) of the linear part of the flexible rotor/casing SFD system. The upper diagram (Figure 3 (a)) shows the rotor deformation and the lower diagram (Figure 3 (b)) the casing centreline deformation. It is noted that, in the current system, the first mode in each plane will be a $0 \mathrm{~Hz}$ mode defining rigid body pivoting motion of the "sprung-free" rotor about the lefthand sprung support, with no casing motion.
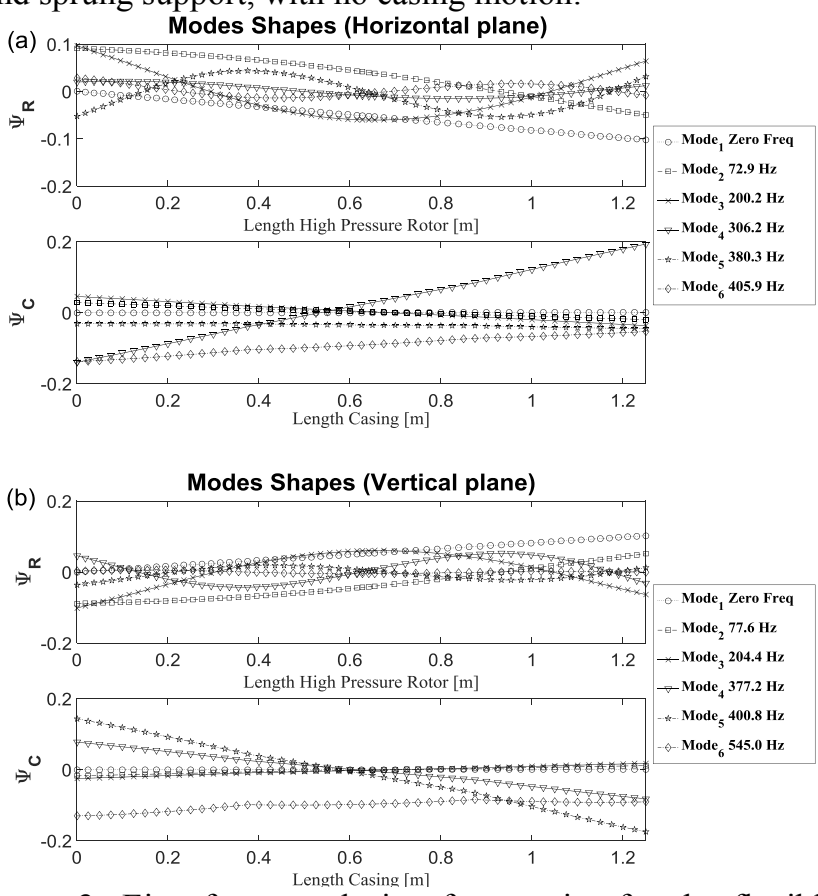

Figure 3: Eigenforms and eigenfrequencies for the flexible rotor/casing SFD system. (a) Horizontal plane; (b) Vertical plane.

\section{THEORY}

\subsection{Forward problem}

The forward problem is considered in this work only to generate the casing vibration data for the following purposes: (1) to provide the data required to solve the inverse problem; (2) to investigate the improvements to the unbalance response after the corrective (balancing) action that was informed by the inverse problem solution has been applied to the rotor. The data in step (1) is generated using the actual balance, that is typically distributed over several planes ( 10 planes in this work). The inverse problem then uses this data to identify the equivalent unbalance, which is assumed to be distributed over a limited number of prescribed planes (3 planes in this work). The data in step (2) is generated from an unbalance distribution that combines the original unbalance used in step (1) with the balancing action (which is the reverse of the equivalent unbalance distribution found from the inverse problem).

The forward problem is defined by the modal equation of motion of the flexible rotor/casing SFD system in the time domain, which are integrated for $\mathbf{q}, \dot{\mathbf{q}}$, given a known excitation $\mathbf{f}_{\mathbf{u}}$ :

$$
\ddot{\mathbf{q}}+\Lambda \mathbf{q}=\sum_{n=1}^{2} \mathbf{H}_{\mathbf{v}_{n}}{ }^{\mathrm{T}} \mathbf{f}_{\mathbf{v}_{n}}\left(\mathbf{v}_{n}, \dot{\mathbf{v}}_{n}\right)+\mathbf{H}_{\mathbf{u}}{ }^{\mathrm{T}} \mathbf{f}_{\mathbf{u}}(t)+\mathbf{H}_{\mathbf{g}}{ }^{\mathrm{T}} \mathbf{g}+\mathbf{H}_{\mathbf{J}_{2}}{ }^{\mathrm{T}} \mathbf{w}
$$

In equation (1), $\mathbf{q}$ is the $R \times 1$ vector of modal coordinates, $\boldsymbol{\Lambda}$ is the diagonal matrix of the squares of the eigenfrequencies $\omega_{1}, \ldots, \omega_{R} \cdot \mathbf{f}_{\mathbf{v}_{n}}\left(\mathbf{v}_{n}, \dot{\mathbf{v}}_{n}\right)$ contains the Cartesian components of the force on the journal at SFD $n(n=1,2)$ which are non-linear functions of the instantaneous displacements and velocities of the journal centres (marked ' $\mathrm{J}_{1 \text { or } 2}$ ' in Figure 2) relative to the centres of their housings (marked ' $\mathrm{B}_{1 \text { or } 2}$ ' in Figure 2 ). The vector $\mathbf{v}_{n}$ contains the instantaneous Cartesian $(x, y)$ displacements of $\mathrm{J}_{n}$ relative to $\mathrm{B}_{n}$, and can be expressed as:

$$
\mathbf{v}_{n}=\mathbf{H}_{\mathbf{v}_{n}} \mathbf{q}+\mathbf{e}_{0_{n}}
$$

where the term $\mathbf{H}_{\mathbf{v}_{n}}$ is the $2 \times R$ matrix whose columns are

$$
\boldsymbol{\Psi}_{\mathbf{v}_{n}}^{(r)}=\boldsymbol{\Psi}_{\mathbf{J}_{n}}^{(r)}-\boldsymbol{\Psi}_{\mathbf{B}_{n}}^{(r)}, \quad r=1 \ldots R
$$

where the vectors $\boldsymbol{\Psi}_{\mathbf{J}_{n}}^{(r)}, \boldsymbol{\Psi}_{\mathbf{B}_{n}}^{(r)}$ are the mass-normalised eigenvectors of defining the $x, y$ displacements of the squeezefilm terminals $\mathrm{J}_{n}, \mathrm{~B}_{n}$ respectively in mode no. $r(r=1 \ldots R)$. The term $\mathbf{e}_{0_{1}}$ (sprung SFD) represents the static offset of the journal relative to their housing, in $x, y$ direction. On the other hand, the vector $\mathbf{e}_{0_{2}}=0$ (i.e. it is omitted) since SFD no. 2 is unsupported and the effect of the static loading on journal $\mathrm{J}_{2}$ in the $x, y$ directions is considered in the $2 \times 1$ vector $\mathbf{w}$.

The vector $\mathbf{f}_{\mathbf{u}}$ comprises the unbalance forces, which are defined as follows:

$$
\mathbf{f}_{\mathbf{u}}=\left[\begin{array}{lllllll}
U_{x_{1}} & U_{y_{1}} & U_{x_{2}} & U_{y_{2}} & \cdots & U_{x_{n_{\text {unb }}}} & U_{y_{n_{\text {unb }}}}
\end{array}\right]^{\mathrm{T}}
$$

where the unbalance forces $U_{x_{k}}, U_{y_{k}} k=1,2,3, \ldots, n_{\text {unb }}$ are presumed to be concentrated at disk positions $k=$ $1,2,3, \ldots, n_{\text {unb }}$ :

$$
\begin{gathered}
U_{x_{k}}=U_{k} \Omega^{2} \sin \left(\Omega t+\gamma+\phi_{k}\right) \\
U_{y_{k}}=-U_{k} \Omega^{2} \cos \left(\Omega t+\gamma+\phi_{k}\right)
\end{gathered}
$$

where the unbalance (in $\mathrm{kg} \mathrm{m}$ ) is denoted by $U_{k}$ at disk no. $k$, and $\phi_{k}$ represents its angular location with as compared to the arbitrary reference phasor (a marker on the rotor) which is displaced by an angle $\Omega t$ from the (stationary) phase probe, that is at an angle $\gamma$ from the downward vertical (Figure 4(a)). Additionally, Figure 4(b) presents the unbalance distribution at ten unbalance locations over the HP rotor coinciding with the disks of the systems, comprising the couplings disks as one can see in Figure 2. 
(a)

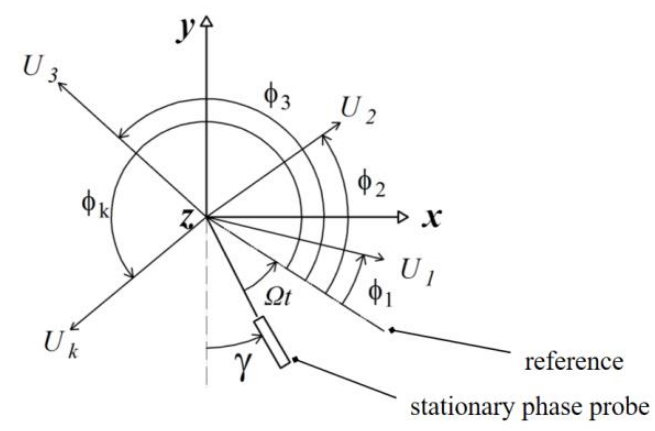

(b)

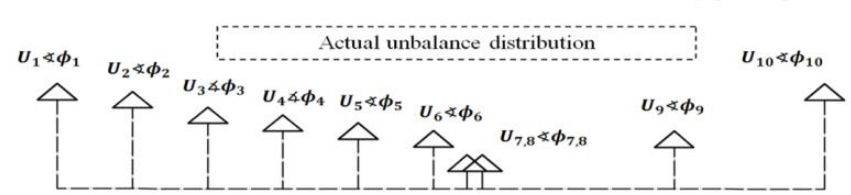

Figure 4: The Rotation of the out-of-unbalance forces: (a) angular of unbalance distribution, respecting with the reference phasor and stationary phase probe; (b) axial unbalance distribution over ten positions [2].

As previously stated in $[2,10,13,14]$, the gyroscopic effects are typically discretized at a number $G$ of locations on the rotor. The vector $\mathbf{g}$ comprises the gyroscopic effects, which are considered external to the non-linear part:

$$
\mathbf{g}=\mathbf{P} \dot{\boldsymbol{\theta}}
$$

where $\mathbf{g}=\left[\begin{array}{lllll}M_{1} & N_{1} & \ldots & M_{G} & N_{G}\end{array}\right]^{\mathrm{T}}$, and $\boldsymbol{\theta}=\left[\begin{array}{lllll}\beta_{1} & \alpha_{1} & \ldots & \beta_{G} & \alpha_{G}\end{array}\right]^{\mathrm{T}}$ (see the coordinate system of Figure 1). $\mathbf{P}=\Omega \operatorname{diag}\left\{-I_{1}, I_{1}, \ldots \ldots,-I_{G}, I_{G}\right\}$, where $I_{p}$ is the polar moment of inertia at position $p(p=1, \ldots, G)$. During the implicit time domain integration of eq. (1), the vector $\dot{\boldsymbol{\theta}}$ is evaluated from $\dot{\mathbf{q}}$ using modal transformation similar to Equation (2).

The columns of the modal matrices $\mathbf{H}_{\mathbf{u}}\left(2 n_{\text {unb }} \times R\right)$ and $\mathbf{H}_{\mathbf{g}}$ $(2 G \times R)$ are represented by $\boldsymbol{\psi}_{\mathbf{u}}^{(r)}, \boldsymbol{\Psi}_{\mathbf{g}}^{(r)}$ respectively and the eigenvectors evaluated at the locations and directions of the entries in $\mathbf{f}_{\mathbf{u}}, \mathbf{g}$.

\subsection{Explicit inverse operator.}

As mentioned in [2], equation (1) can be transposed in frequency domain and condensed from modal coordinates to any selected physical degrees of freedom using RHBM [10]. The RHBM equations relate the Fourier coefficients of any harmonic of the response with the Fourier coefficients of the excitation forces on the linear part at that harmonic using frequency response functions ("receptances") [16].

The operator to solve the inverse problem [2] is formulated in terms of vibration velocity readings from the casing. A detailed description of the inverse balancing method is provided in [2]. It is assumed that the vibration is periodic at a fundamental frequency equal to the rotational speed $\Omega[10]$. Hence, the unbalance force term only appears in that subset of the RHBM equations relating to the synchronous harmonic [2]. However, it should be emphasized that this inverse balancing method can applied for vibration with synchronous and non-synchronous harmonics [2,9]. The synchronous subset of the RHBM equations, which describe the dynamic velocity response at the casing, are written as follows [2]:

$$
\left[\begin{array}{c}
\mathbf{z}_{\mathbf{p}_{i \mathrm{~S}}}^{(1)} \\
\mathbf{z}_{\mathbf{p}_{i \mathrm{C}}}^{(1)}
\end{array}\right]=\mathbf{A}_{i}(\Omega)\left[\begin{array}{c}
\mathbf{f}_{\mathbf{v}_{\mathrm{c}}}^{(1)} \\
\mathbf{f}_{\mathbf{v}_{\mathrm{s}}}^{(1)}
\end{array}\right]+\mathbf{B}_{i}(\Omega)\left[\begin{array}{l}
\widehat{\mathbf{u}}_{\mathrm{C}} \\
\widehat{\mathbf{u}}_{\mathrm{S}}
\end{array}\right] \quad\left(i=1 \ldots n_{\mathrm{s}}\right)
$$

where:

$$
\begin{array}{r}
\mathbf{A}_{i}(\Omega)=\left[\begin{array}{cc}
-\mathbf{M}_{\mathbf{p}_{i} \mathbf{v}}(\Omega)+\mathbf{E}_{i}(\Omega) & -\mathbf{F}_{i}(\Omega) \\
\mathbf{F}_{i}(\Omega) & \mathbf{M}_{\mathbf{p}_{i} \mathbf{v}}(\Omega)-\mathbf{E}_{i}(\Omega)
\end{array}\right] \\
\mathbf{B}_{i}(\Omega)=\Omega^{2}\left[\begin{array}{cc}
-\mathbf{M}_{\mathbf{p}_{i} \hat{\mathbf{u}}}(\Omega)+\mathbf{L}_{i}(\Omega) & -\mathbf{Q}_{i}(\Omega) \\
-\mathbf{Q}_{i}(\Omega) & \mathbf{M}_{\mathbf{p}_{i} \hat{\mathbf{u}}}(\Omega)-\mathbf{L}_{i}(\Omega)
\end{array}\right]
\end{array}
$$

where

$$
\begin{aligned}
& \mathbf{E}_{i}(\Omega)=\mathbf{M}_{\mathbf{p}_{i} \mathbf{g}}(\Omega) \Omega \mathbf{P D}(\Omega) \breve{\mathbf{B}}(\Omega) \mathbf{C}_{\theta \mathbf{v}}(\Omega) \\
& \mathbf{F}_{i}(\Omega)=\mathbf{M}_{\mathbf{p}_{i} \mathbf{g}}(\Omega) \Omega \mathbf{P D}(\Omega) \mathbf{C}_{\theta \mathbf{v}}(\Omega) \\
& \mathbf{L}_{i}(\Omega)=\mathbf{M}_{\mathbf{p}_{i} \mathbf{g}}(\Omega) \Omega \mathbf{P D}(\Omega) \breve{\mathbf{B}}(\Omega) \mathbf{C}_{\theta \widehat{\mathbf{u}}}(\Omega) \\
& \mathbf{Q}_{i}(\Omega)=\mathbf{M}_{\mathbf{p}_{i} \mathbf{g}}(\Omega) \Omega \mathbf{P D}(\Omega) \mathbf{C}_{\theta \widehat{\mathbf{u}}}(\Omega)
\end{aligned}
$$$$
\mathbf{M}_{\mathbf{p}_{i} \mathbf{v}}=\Omega \mathbf{C}_{\mathbf{p}_{i} \mathbf{v}}(\Omega), \mathbf{M}_{\mathbf{p}_{i} \mathbf{g}}(\Omega)=\Omega \mathbf{C}_{\mathbf{p}_{i} \mathbf{g}}(\Omega), \mathbf{M}_{\mathbf{p}_{i} \widehat{\mathbf{u}}}=\Omega \mathbf{C}_{\mathbf{p}_{i} \widehat{\mathbf{u}}}(\Omega)
$$

Where

$$
\mathbf{D}(\Omega)=\left(\mathbf{I}+(\breve{\mathbf{B}})^{2}\right)^{-\mathbf{1}}, \quad \breve{\mathbf{B}}(\Omega)=\mathbf{C}_{\theta \mathbf{g}}(\Omega) \Omega \mathbf{P}
$$

In the above equations, the reacceptances matrices are defined from modal theory [16] as:

$$
\begin{gathered}
\mathbf{C}_{\mathbf{p}_{i} \mathbf{v}}(\Omega)=\sum_{r=1}^{R} \frac{\boldsymbol{\psi}_{\mathbf{p}_{i}}^{(r)} \boldsymbol{\Psi}_{\mathrm{v}}^{(r)}}{\omega_{r}^{2}-\Omega^{2}}, \mathbf{C}_{\mathbf{p}_{i} \mathbf{g}}(\Omega)=\sum_{r=1}^{R} \frac{\boldsymbol{\psi}_{\mathbf{p}_{i}}^{(r)} \boldsymbol{\psi}_{\mathrm{g}}^{(r)^{\mathrm{T}}}}{\omega_{r}^{2}-\Omega^{2}}, \\
\mathbf{C}_{\mathbf{p}_{i} \hat{\mathbf{u}}}(\Omega)=\sum_{r=1}^{R} \frac{\left.\boldsymbol{\psi}_{\mathbf{p}_{i}}^{(r)} \boldsymbol{\psi}_{\mathbf{u}}^{(r)}\right)^{\mathrm{T}}}{\omega_{r}^{2}-\Omega^{2}}
\end{gathered}
$$

and

$$
\begin{gathered}
\mathbf{C}_{\boldsymbol{\theta} \mathbf{v}}(\Omega)=\sum_{r=1}^{R} \frac{\boldsymbol{\psi}_{\theta}^{(r)} \boldsymbol{\Psi}_{\mathbf{v}}^{(r)}}{\omega_{r}^{2}-\Omega^{2}}, \mathbf{C}_{\boldsymbol{\theta} \mathbf{g}}(\Omega)=\sum_{r=1}^{R} \frac{\boldsymbol{\psi}_{\theta}^{(r)} \boldsymbol{\Psi}_{\mathbf{g}}^{(r)^{\mathrm{T}}}}{\omega_{r}^{2}-\Omega^{2}}, \\
\mathbf{C}_{\boldsymbol{\theta} \widehat{\mathbf{u}}}(\Omega)=\sum_{r=1}^{R} \frac{\boldsymbol{\Psi}_{\theta}^{(r)} \boldsymbol{\Psi}_{\mathbf{u}}^{(r)}}{\omega_{r}^{2}-\Omega^{2}}
\end{gathered}
$$

where $\boldsymbol{\Psi}_{\mathbf{p}_{i}}^{(r)}, \boldsymbol{\Psi}_{\widehat{\mathbf{u}}}^{(r)}, \boldsymbol{\Psi}_{\mathrm{g}}^{(r)}, \boldsymbol{\Psi}_{\boldsymbol{\theta}}^{(r)}, \boldsymbol{\Psi}_{\mathbf{v}}^{(r)}$ are the eigenvectors evaluated at the degrees of freedom corresponding to the entries in $\mathbf{x}_{\mathbf{p}_{i}}, \mathbf{f}_{\widehat{\mathbf{u}}}, \mathbf{g}, \boldsymbol{\theta}$ and $\mathbf{f}_{\mathbf{v}}$ respectively in mode no. $r(r=1 \ldots R)$.

Equation (7) constitutes the dynamic block of the RHBM equations from the engine casing [2]. The vector $\left[\begin{array}{ll}\boldsymbol{z}_{\boldsymbol{p}_{i_{S}}}^{(1)} & \boldsymbol{z}_{\boldsymbol{p}_{i_{C}}}^{(1)}\end{array}\right]^{\mathrm{T}}$, comprised the synchronous Fourier coefficients extracted from the velocity readings at each located sensor over the casing. As noted in [2], it is possible to obtain the vector $\left[\begin{array}{ll}\mathbf{f}_{\mathbf{v}_{\mathbf{c}}}^{(1)} & \mathbf{f}_{\mathbf{v}_{\mathbf{s}}}^{(1)}\end{array}\right]^{\mathrm{T}}$, which contains the synchronous Fourier 
coefficients of the SFD forces at each SDF terminal. The subscripts $\mathrm{S}$ and $\mathrm{C}$ correspond to Fourier Cosine and Sine coefficients, respectively. Figure 5 shows the sensor locations, which are evenly distributed along the casing. Hence, the sensors located at each SFD terminal $\left(\mathbf{P}_{\mathbf{S F D}_{1}}\right.$ and $\left.\mathbf{P}_{\mathbf{S F D}_{2}}\right)$ were chosen as the reference locations.

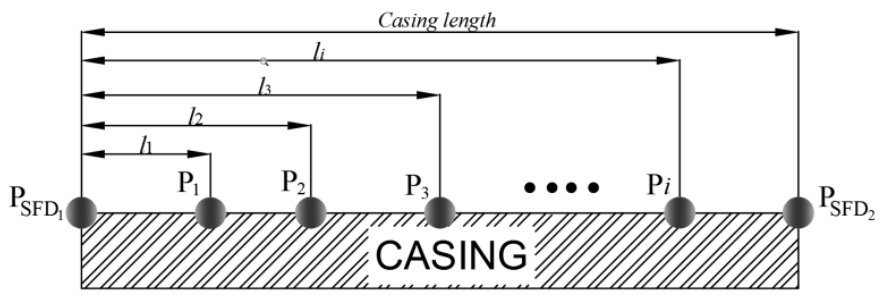

Figure 5: The locations of the sensor over the casing

With reference to Figure 5 and rearranging equation (7), the synchronous components of the nonlinear forces at the SFD locations can be expressed in terms of the unbalance and the synchronous components of the velocity measurements at an equal number of reference sensor locations, in this case 2 references, resulting in the following expression:

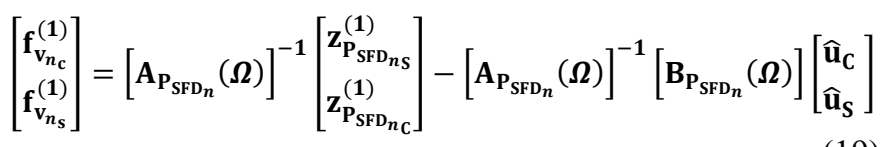

where $\mathbf{P}_{\mathbf{S F D}_{n}}$ is the sensor reference location at SFD no. $n$, which was previously described in section 3.1. The above expression for $\mathbf{f}_{\mathbf{v}_{n_{\mathbf{C}}}}^{(1)}, \mathbf{f}_{\mathbf{v}_{\boldsymbol{n}_{\mathrm{S}}}}^{(1)}$ can be back-substituted into equation (7). However, the present system case requires two sensor locations (e. g. for $i=1,2 ; 3,4 ; 5,6 ; \ldots ; 2 n_{s}$ ) resulting:

$$
\mathbf{z}(\Omega)=\mathbf{U}(\Omega)\left[\begin{array}{l}
\widehat{\mathbf{u}}_{\mathrm{C}} \\
\widehat{\mathbf{u}}_{\mathrm{S}}
\end{array}\right]
$$

where

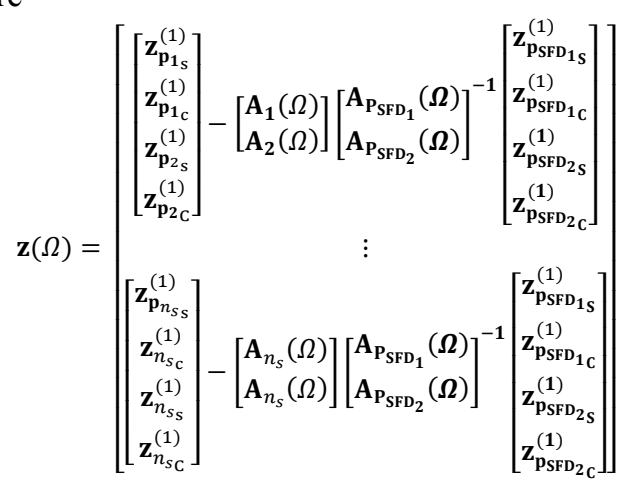

and

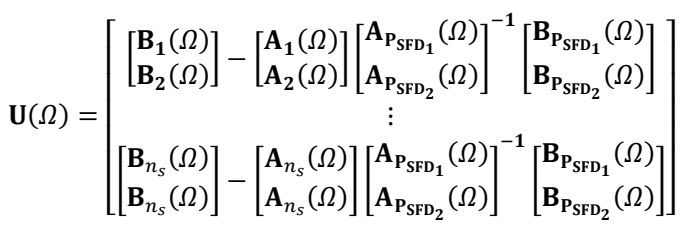

As in [2,9], equation (20) can be augmented over a set of operating speeds $\Omega_{k}, k=1 \ldots n_{\mathrm{o}}$.

where

$$
\mathbf{z}_{\text {aug }}=\mathbf{U}_{\mathrm{aug}}\left[\begin{array}{l}
\widehat{\mathbf{u}}_{\mathrm{C}} \\
\widehat{\mathbf{u}}_{\mathrm{S}}
\end{array}\right]
$$

$$
\mathbf{z}_{\text {aug }}=\left[\begin{array}{c}
\vdots \\
\mathbf{z}\left(\Omega_{k}\right) \\
\vdots
\end{array}\right], \quad \mathbf{U}_{\text {aug }}=\left[\begin{array}{c}
\vdots \\
\mathbf{U}\left(\Omega_{k}\right) \\
\vdots
\end{array}\right]
$$

\subsection{Inverse solution and inclusion of balancing forces}

As in [2], the inversion process finds the elements of the coefficient vectors $\widehat{\mathbf{u}}_{\mathrm{C}}, \widehat{\mathbf{u}}_{\mathrm{S}}$. In this research three balancing planes are also used and so:

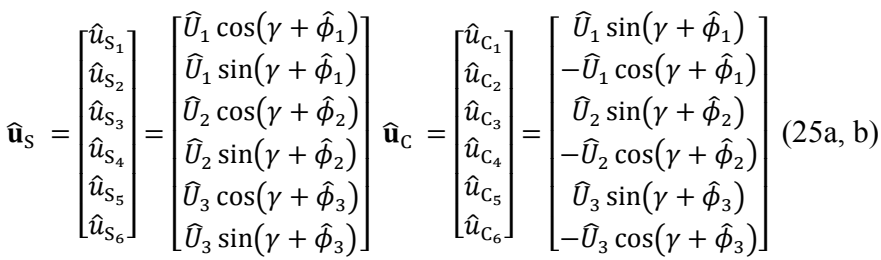

As noted at the beginning of section 3.1, the actual unbalances $U_{1}, U_{2}, U_{3}, \ldots$ will generally reside in more than three planes (Figure $4(\mathrm{~b})$ ) and the three equivalent unbalances $\widehat{U}_{1}, \widehat{U}_{2}, \widehat{U}_{3}$ will not be at the locations of $U_{1}, U_{2}, U_{3}$ (see Figure 6). However, the angular displacements $\hat{\phi}_{k}$ are with respect to the same reference phasor marker (the line that is displaced by $\Omega t$ from the phase probe in Figure 4(a) and Figure 6(a)). It is noted that the locations of $\widehat{U}_{1}, \widehat{U}_{2}, \widehat{U}_{3}$ are the balancing planes, where unbalances equal and opposite to $\widehat{U}_{1}$, $\widehat{U}_{2}, \widehat{U}_{3}$ will be applied once these are estimated.

(a)

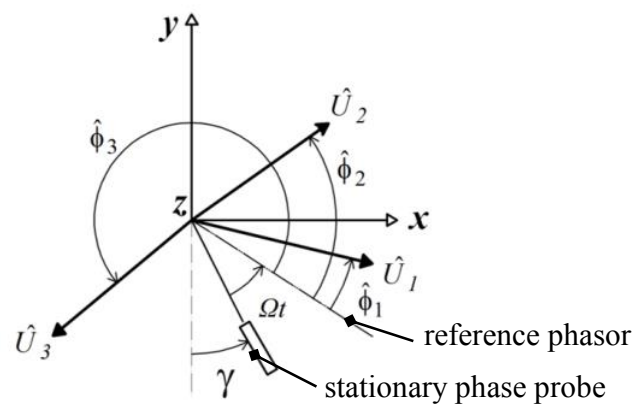

(b)

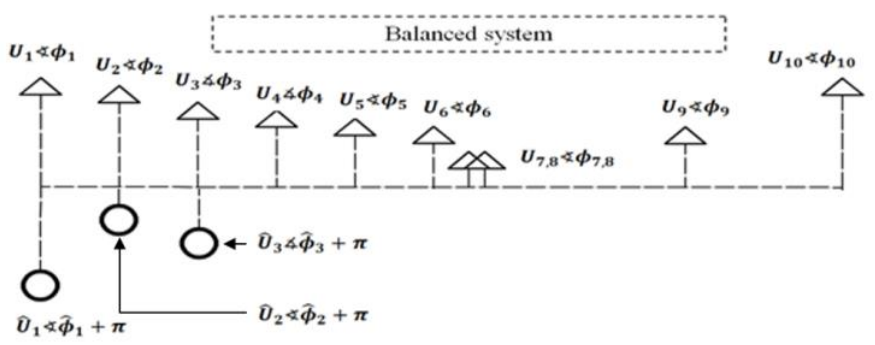

Figure 6: Equivalent unbalance forces \& their inclusions: (a) angular distribution of unbalance, with respect to reference phasor and stationary phase probe; (b) balanced SFD system. 
As in previous work [2], the elements of $\widehat{\mathbf{u}}_{\mathrm{C}}, \widehat{\mathbf{u}}_{\mathrm{S}}$ from equation (23) might be identified via singular value decomposition (SVD):

$$
\left[\begin{array}{l}
\widehat{\mathbf{u}}_{\mathrm{C}} \\
\widehat{\mathbf{u}}_{\mathrm{S}}
\end{array}\right]=\mathbf{U}_{\mathrm{aug}}{ }^{+} \mathbf{z}_{\mathrm{aug}}
$$

where $\mathbf{U}_{\text {aug }}{ }^{+}$denotes the pseudo-inverse of $\mathbf{U}_{\text {aug }}$. Therefore, the matrix $\mathbf{U}_{\text {aug }}{ }^{+}$can be expressed by using SVD formulation as:

$$
\mathbf{U}_{\text {aug }}{ }^{+}=\mathbf{V} \boldsymbol{\Sigma}^{+} \mathbf{Y}^{\mathrm{T}}
$$

where, if $\mathbf{U}_{\text {aug }}$ is of size $m \times n: \mathbf{Y}$ is $m \times m$ matrix whose columns are the eigenvectors of $\mathbf{U}_{\text {aug }} \mathbf{U}_{\text {aug }}{ }^{\mathrm{T}}, \mathbf{V}$ is $n \times n$ matrix whose columns are the eigenvectors of $\mathbf{U}_{\text {aug }}{ }^{\mathrm{T}} \mathbf{U}_{\text {aug }}$, and $\boldsymbol{\Sigma}^{+}$is the $n \times m$ matrix given by

$$
\boldsymbol{\Sigma}^{+}=\left[\begin{array}{cccc}
\operatorname{diag}\left(\sigma_{1}^{-1}\right. & \cdots & \left.\sigma_{K}^{-1}\right) & \mathbf{0} \\
& \mathbf{0} & & \mathbf{0}
\end{array}\right]
$$

$\sigma_{1}, \ldots \sigma_{K}$ being the $K$ non-zero singular values of $\mathbf{U}_{\text {aug }}$.

As previously stated in [2,9], having identified the elements of $\widehat{\mathbf{u}}_{\mathrm{C}}, \widehat{\mathbf{u}}_{\mathrm{S}}$, there are two possibilities for estimating the equivalent unbalance $\widehat{U}_{k}, \quad k=1,2,3$ and its angular displacement $\hat{\phi}_{k}$ relative to the reference phasor (Figure 6a), using either $\widehat{\mathbf{u}}_{\mathrm{S}}$ (i.e. Equation (25(a))

$$
\widehat{U}_{k}=\sqrt{\left(\hat{u}_{S_{2 k-1}}\right)^{2}+\left(\hat{u}_{S_{2 k}}\right)^{2}},\left\{\begin{array}{l}
\cos \left(\gamma+\hat{\phi}_{k}\right)=\hat{u}_{S_{2 k-1}} / \widehat{U}_{k} \\
\sin \left(\gamma+\widehat{\phi}_{k}\right)=\hat{u}_{S_{2 k}} / \widehat{U}_{k}
\end{array}\right.
$$

or $\widehat{\mathbf{u}}_{\mathrm{C}}$ (i.e. Equation $(25(\mathrm{~b}))$

$$
\widehat{U}_{k}=\sqrt{\left(\hat{u}_{\mathrm{C}_{2 k-1}}\right)^{2}+\left(\hat{u}_{\mathrm{C}_{2 k}}\right)^{2}},\left\{\begin{array}{c}
\sin \left(\gamma+\hat{\phi}_{k}\right)=\hat{u}_{\mathrm{C}_{2 k-1}} / \widehat{U}_{k} \\
\cos \left(\gamma+\widehat{\phi}_{k}\right)=-\hat{u}_{\mathrm{C}_{2 k}} / \widehat{U}_{k}
\end{array}\right.
$$

Henceforth, the balancing force vector $\mathbf{f}_{\mathbf{b}}$, comprising forces with phasors equal and opposite to the estimated equivalent unbalance forces (Figure 6(b)), might be structured as follows:

$$
\mathbf{f}_{\mathbf{b}}=\left[\begin{array}{c}
\Omega^{2} \widehat{U}_{1} \sin \left(\Omega t+\gamma+\left(\hat{\phi}_{1}+\pi\right)\right) \\
-\Omega^{2} \widehat{U}_{1} \cos \left(\Omega t+\gamma+\left(\widehat{\phi}_{1}+\pi\right)\right) \\
\Omega^{2} \widehat{U}_{2} \sin \left(\Omega t+\gamma+\left(\hat{\phi}_{2}+\pi\right)\right) \\
-\Omega^{2} \widehat{U}_{2} \cos \left(\Omega t+\gamma+\left(\hat{\phi}_{2}+\pi\right)\right) \\
\Omega^{2} \widehat{U}_{3} \sin \left(\Omega t+\gamma+\left(\hat{\phi}_{3}+\pi\right)\right) \\
-\Omega^{2} \widehat{U}_{3} \cos \left(\Omega t+\gamma+\left(\hat{\phi}_{3}+\pi\right)\right)
\end{array}\right]
$$

These balancing forces are then added to the actual unbalanced system in Figure 4(b), to yield the "balanced" system in Figure 6(b).

\section{GENERATION OF SIMULATED VIBRATION DATA.}

As previously done in $[1,2,9]$, the current study-case employed simulated casing vibration data, since the actual balancing measurements from an aircraft engine are difficult to obtain. This simulated data were computed by solving the forward problem (eq. (1)) in the time domain for the SFD system described in Figure 2. These simulated data were then employed for the balancing and testing.

Unlike to the highly idealized SFD model used in [1], the SFD forces were computed using the more realistic approach used in $[2,9,10,13,14]$, as appropriate for whole-engine modelling. The instantaneous pressure distribution in the SFD was approximated by a combination of the short and long bearing expressions through an "end-leakage" factor of 0.1 which represents the degree of end-sealing. This distribution was truncated below a cavitation pressure of absolute zero ($101.325 \mathrm{kPa}$ ) and numerically integrated across the oil film to generate SFD forces.

As in $[2,9,10,13]$,the SFD bearings considered for this study case were single-land and end-fed with oil of viscosity 0.0049 $\mathrm{nsm}^{-2}$ at a pressure of $3 \mathrm{bar}$ (gauge). The bearing diameter and radial clearance were $220 \mathrm{~mm}, 0.12 \mathrm{~mm}$ respectively, and the land length was $26 \mathrm{~mm}$.

For the SFD system described in Figure 2, equation (1) was solved at discrete operational speeds using the implicit time domain integrator ode $23 s \subseteq$ available in MATLAB ${ }^{\circledR}[18]$. The vector $\mathbf{f}_{\mathbf{u}}$ was due to the seeded unbalance distribution shown in Figure 4(b) and described in Table 1. Unless otherwise stated (section 3.1), the reference phasor probe position $\gamma$ (Figure $4(\mathrm{a})$ ) is taken to be $0^{\circ}$.

\begin{tabular}{|c|c|c|c|c|c|c|c|c|c|c|}
\hline$k$ & 1 & 2 & 3 & 4 & 5 & 6 & 7 & 8 & 9 & 10 \\
\hline$U_{k}$ & 0.1 & 0.5 & 0.1 & 1.0 & 0.5 & 1.0 & 0.1 & 1.5 & 0.3 & 1.5 \\
\hline$\phi_{k}$ & 0 & 110 & 305 & 85 & 195 & 145 & 75 & 10 & 215 & 330 \\
\hline \multicolumn{1}{|c|}{ NB: Unbalance $\left[\times 10^{-3} \mathrm{~kg} \mathrm{~m}\right]$, phase angle $\left[\times 180 / \pi\left(^{\circ}\right)\right]$} \\
\hline
\end{tabular}

Table 1: Seeded unbalance distribution [2]

The forward calculation considered $R=12$ modes (i.e. 6 modes in each of the horizontal and vertical planes). For the sprung SFD case was given high static offset $\mathbf{e}_{\mathbf{0}}=$ $\left[\begin{array}{ll}0.5 c & -0.75 c\end{array}\right]^{\mathrm{T}}$ for the compressor-end bearing as in [2]. As noted in [2] and described in Section 3.1, in the unsupported SFD case, the eccentric mean position of the journal is determined by the equilibrium between the equivalent rotor weight at the journal and the mean SFD forces.
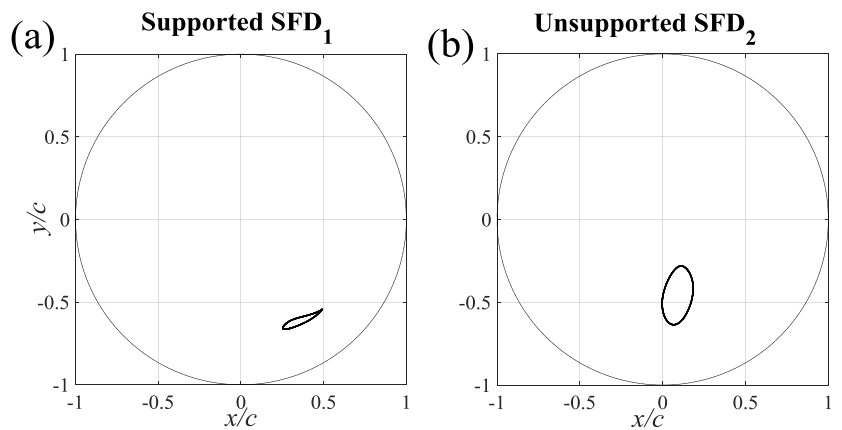

Figure 7: SFD Orbits from relative displacements before balancing at each SFD terminal. a) Supported SFD. b) Unsupported SFD. $\Omega=8500$ RPM 
As previous work [2,9], the steady-state part of the time histories of $\mathbf{q}$ and $\dot{\mathbf{q}}$ were then used to calculate the simulated velocity sensor readings at the casing as follows:

$$
\dot{\mathbf{x}}_{\mathbf{p}}=\mathbf{H}_{\mathrm{M}} \dot{\mathbf{q}}
$$

where $\dot{\mathbf{x}}_{\mathbf{p}}$ is the $2 n_{\mathrm{s}} \times 1$ vector of velocity readings, alternately in the $x, y$ directions at $n$ s locations along the casing (an $x$ vibration sensor and a $y$ vibration sensor at each location):

$$
\dot{\mathbf{x}}_{\mathbf{p}}=\left[\begin{array}{c}
\vdots \\
\dot{\mathbf{x}}_{\mathbf{p}_{i}} \\
\vdots
\end{array}\right]
$$

$\mathbf{H}_{\mathbf{M}}$ is the $2 n_{\mathrm{s}} \times R$ matrix whose $R$ columns are the eigenvectors evaluated at the sensor locations $\mathrm{P}_{i}, i=1 \ldots n_{\mathrm{s}}$, alternately in the $x, y$ directions.

$$
\mathbf{H}_{\mathbf{M}}=\left[\begin{array}{ccc}
\vdots & \cdots & \vdots \\
\boldsymbol{\Psi}_{\mathbf{p}_{i}}^{(1)} & \cdots & \boldsymbol{\Psi}_{\mathbf{p}_{i}}^{(R)} \\
\vdots & \cdots & \vdots
\end{array}\right]
$$

In contrast to [2], the number of sensors locations evenly distributed along the casing will be increased (see Figure 5). In section 5.2 will show the effect in the balancing effectiveness, when $n_{\mathrm{s}}$ will be augmented.

To investigate the effectiveness of the inverse balancing method [2], the forward solution process was repeated for the "balanced" system in Figure 6 (b). Equation (1) was therefore solved again with the inclusion of an additional unbalance term $\mathbf{H}_{\mathbf{b}}{ }^{\mathrm{T}} \mathbf{f}_{\mathbf{b}}$ to the right-hand side of equation (1) where $\mathbf{H}_{\mathbf{b}}$ is the $6 \times R$ matrix whose columns are the eigenvectors evaluated in the $x, y$ directions at the prescribed balancing locations along the rotor and the vector $\mathbf{f}_{\mathbf{b}}$ comprises the balancing forces which was defined in equation (30).

\section{TESTING CASES AND DISCUSSION. \\ 5.1 Balancing methodology}

The inverse problem balancing procedure involves the following three stages [2]:

(i) To begin this procedure, it is required to take casing vibration data for the unbalanced system (Figure 4(b) and Table 1) from various sensors locations as illustrated in Figure 4. In contrast to [2], the current case of study involves two types of testing: (a) to analyse the influence of the condition number; (b) how it is affected as the number of sensors and/or measurement speeds are increased. The collected vibration data from the chosen sensor location at selected operational speeds are used to build up equation (23).

(ii) The following step consists in the selection of the prescribed balancing planes to conduct the equivalent unbalance identification at these planes, as per section 3.2. The previous studies [2,9] studied an SFD rotodynamic system which consisted of one strong linear connection at one end (a rolling element bearing with SFD annulus) and an unsupported SFD at the other. It was noted that the best balancing effectiveness was obtained when the unbalance planes were chosen as close as possible to the only linear connection. Hence, in the current system case the selected unbalance planes are at disks 1,2,3, which are close to the only linear connection S3 (see Figure 2). As previously mentioned in section 3.2, the explicit construction inverse operator employs two reference locations $\left(\mathrm{P}_{\mathrm{SFD}_{1}}\right.$ and $\mathrm{P}_{\mathrm{SFD}_{2}}$, see Figure (5)) to express the forces at the two SFDs in terms of the unbalance and the synchronous components of the velocity measurements (see Equation (19). It is important to mention that all presented results use the same reference locations and the same prescribed unbalance planes.

(iii) The third and final step is to add the balancing forces to the unbalanced rotor (as in Figure 6(b)) and obtain new casing vibration data. The degree of effectiveness of the balancing solution can then be quantified by the calculation of the average percentage vibration velocity amplitude reduction (PVR) at each sensor location $\mathrm{P}_{i}$ over the speeds at which the vibration readings were taken[2] :

$$
\operatorname{PVR}\left(\mathrm{P}_{i}\right)=\left.\overline{\left(\frac{A_{\text {before }} A_{\text {after }}}{A_{\text {before }}}\right)}\right|_{\Omega_{k}, k=1 \ldots n_{\mathrm{o}}} \times 100
$$

For the standardization of all presented results, the PVRs were obtained from six sensors locations placed as previous work [2] and the casing vibration measurements (before and after balancing) were obtained at 14 speeds $(8000,8500,9000$, $\ldots, 14000$ and $14500 \mathrm{rpm}$ ) which cover the typical operating speed range of the HP rotor of an aero-engine $[2,10,13,14]$. In addition, it is important to mention that in the following results, unless otherwise stated, the average of the unbalance estimates from the $\widehat{\mathbf{u}}_{\mathrm{S}}$ and $\widehat{\mathbf{u}}_{\mathrm{C}}$ solutions (equations $(29 \mathrm{a}, \mathrm{b})$ ) with the stationary phase probe position $\gamma=0$ (see Figure 6(a)) are used.

\subsection{Increasing the number of sensor locations.}

The aim of this section and the following section is to examine the influence of the condition number of the matrix $\mathbf{U}_{\text {aug }}$ (equation (23)) on the estimation of the equivalent unbalance at three prescribed unbalance planes (see equation $25(\mathrm{a}, \mathrm{b}))$. According to $[17,18]$, the condition number is a measure of nearness to singularity, i.e. the conditioning of the inverse problem deteriorates as the condition number is increased. Typically, its computation requires the SVD to obtain $\mathbf{V}, \boldsymbol{\Sigma}$ and $\mathbf{Y}$ which were previously described in section 3.3. The $K$ non-zero singular values $\left(\sigma_{K}\right)$ of $\mathbf{U}_{\text {aug }}$ are used to compute the condition number as follows [17]:

$$
\kappa\left(\mathbf{U}_{\mathrm{aug}}\right)=\frac{\max \left(\sigma_{K}\right)}{\min \left(\sigma_{K}\right)}
$$

In contrast to [2,9], in the present testing case $\mathbf{z}_{\mathrm{aug}}$ and $\mathbf{U}_{\mathrm{aug}}$ (in equation 23) were constructed by augmenting the number of sensor locations at a fixed number $\left(n_{0}=17\right)$ of measurement speeds to conduct the construction of the explicit inverse operator. The terms $\mathbf{z}_{\text {aug }}$ and $\mathbf{U}_{\text {aug }}$ are therefore redefined as $\left.\mathbf{z}_{\text {aug }_{n_{0}=17}}\right|_{n_{s}}$ and $\left.\mathbf{U}_{\text {aug }_{n_{0}=17}}\right|_{n_{s}}$, where $n_{s}$ is the number of sensor locations employed to construct Equation (23).

\begin{tabular}{|c|c|c|c|}
\hline$n_{s}$ & $\max \left(\sigma_{K}\right)$ & $\min \left(\sigma_{K}\right)$ & $\kappa\left(\left.\mathbf{U}_{\mathrm{aug}_{n_{0}=17}}\right|_{n_{s}}\right)$ \\
\hline 6 & 3.1415 & $4.6114 \times 10^{-5}$ & 68102 \\
\hline 8 & 3.7888 & $5.4123 \times 10^{-5}$ & 70003 \\
\hline 10 & 4.0020 & $5.7770 \times 10^{-5}$ & 69274 \\
\hline 12 & 4.2440 & $6.5127 \times 10^{-5}$ & 65165 \\
\hline
\end{tabular}


Table 2: The condition number of $\left.\mathbf{U}_{\operatorname{aug}_{n_{\mathbf{0}}=17}}\right|_{n_{S}}$

Table 2 provides the values of $\max \left(\sigma_{K}\right)$ and $\min \left(\sigma_{K}\right)$ used to compute $\kappa\left(\left.\mathbf{U}_{\operatorname{aug}_{n_{0}=17}}\right|_{n_{S}}\right)$ over the $n_{S}$ different cases. It is clear from data in Table 2 that the values of $\kappa\left(\left.\mathbf{U}_{\operatorname{aug}_{n_{0}=17}}\right|_{n_{S}}\right)$ are significantly high, and therefore the problem is illconditioned. It was also noticed that the condition numbers of the present study are considerably higher than the reported values in [2]. Another significant observation from Table 2 is that the condition number did not vary significantly as the number of sensor locations was increased.

Figure 8 shows the percentage vibration reduction in the $\mathrm{x}$ and y directions, (denoted by HPVR, VPVR respectively) at six sensor locations after balancing of the system for each of the cases in Table 2 (i.e. vibration data from up to 12 sensor locations were used to construct the matrices of equations $24(a, b))$. It is noted that the balancing effectiveness is affected due to the very high condition numbers, as presented in Table 2. However, it does not simply increase with an increase in the number of sensors.
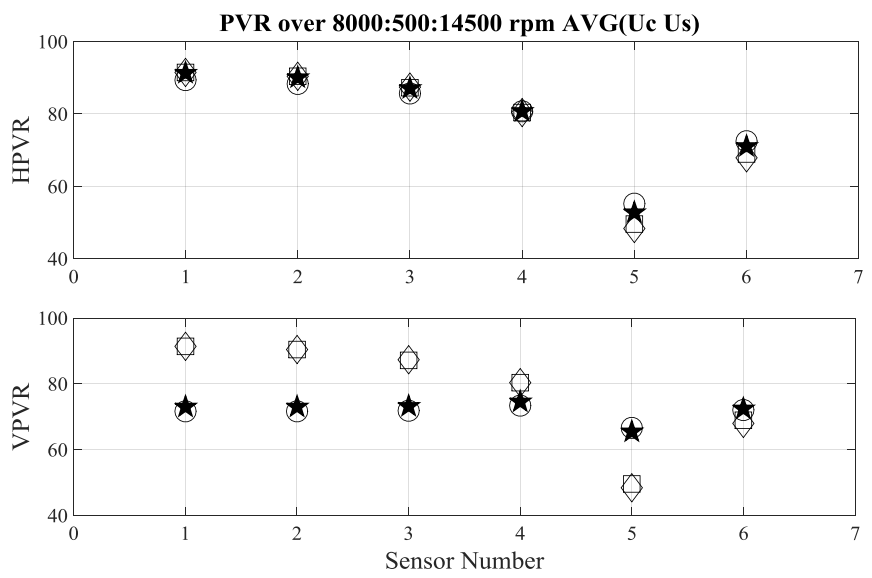

Figure 8: Effect of the conditioning of $\boldsymbol{U}_{\text {aug }}$ on PVRs when the number of sensor locations $\left(n_{s}\right)$ are increased: $n_{s}=6$ locations $(\boldsymbol{\Lambda}) ; n_{s}=8$ locations $(\diamond) ; n_{s}=10$ locations $(\square)$; $n_{s}=12$ locations $(\bigcirc)$;

From the data in Table 2, one can see that cases $n_{s}=6$ and $n_{s}=12$ resulted in the lowest condition number values and Figure 8 shows that $n_{s}=6$ and $n_{s}=12$ produced the most consistent balancing over the six locations plotted. The case $n_{s}=6$ involved the least processing time. Therefore, in the subsequent results, the number sensors used to construct equations $(24 \mathrm{a}, \mathrm{b})$ was taken to be $n_{s}=6$.

\subsection{Increasing the number of measurement speeds.}

For this case, $n_{s}$ was fixed to 6 places and $n_{o}$ was increased (or decreased) to conduct the construction of the explicit inverse operator, as described in Section 3.2. Table 3 below provides the $\max \left(\sigma_{K}\right)$ and $\min \left(\sigma_{K}\right)$ used to compute

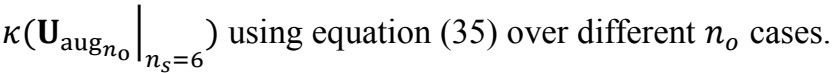

\begin{tabular}{|c|c|c|c|c|}
\hline$n_{\mathrm{o}}$ & ${ }^{*} \operatorname{COS}(\mathrm{rpm})$ & $\max \left(\sigma_{K}\right)$ & $\min \left(\sigma_{K}\right)$ & $\kappa\left(\mathbf{U}_{\left.\left.\mathrm{aug}_{n_{\mathrm{o}}}\right|_{n_{s}=6}\right)}\right.$ \\
\hline 9 & $8000: \Delta_{o}: 12000$ & 1.5860 & $1.4946 \times 10^{-5}$ & 106114 \\
\hline 13 & $8000: \Delta_{o}: 14000$ & 2.0489 & $2.6475 \times 10^{-5}$ & 77387 \\
\hline 15 & $8000: \Delta_{o}: 15000$ & 3.1129 & $3.5245 \times 10^{-5}$ & 88321 \\
\hline 17 & $8000: \Delta_{o}: 16000$ & 3.1415 & $4.6114 \times 10^{-5}$ & 68102 \\
\hline 19 & $8000: \Delta_{o}: 17000$ & 3.1979 & $5.7656 \times 10^{-5}$ & 55178 \\
\hline 21 & $8000: \Delta_{o}: 18000$ & 3.2903 & $7.1797 \times 10^{-5}$ & 45828 \\
\hline \multicolumn{6}{|c|}{$*$ Chosen Operating Speeds, $\Delta_{o}=500 \mathrm{rpm}$} \\
\hline
\end{tabular}

Table 3: The condition number of $\left.\mathbf{U}_{\text {aug }_{n_{\mathrm{o}}}}\right|_{n_{s}=6}$

As Table 3 shows, there is a significant reduction in the condition number, when the number of measurements speeds was increased. It is noted that there is a reduction of around $50 \%$ when the number of speeds is increased from $n_{0}=9$ to $n_{\mathrm{o}}=21$. Theoretically, this should translate to an improvement in the balancing effectiveness. However, the condition number values are still higher than the values reported for the simpler case in [2]. From the data in Figure 9, it is apparent that the balancing effectiveness improves as the number of speeds increases from $n_{\mathrm{o}}=9$ to $n_{\mathrm{o}}=17$. However, the balance effectiveness starts deteriorating with further increase in the number of speeds, particularly as the number of speeds is increased further from $n_{\mathrm{o}}=19$ to $n_{\mathrm{o}}=21$.
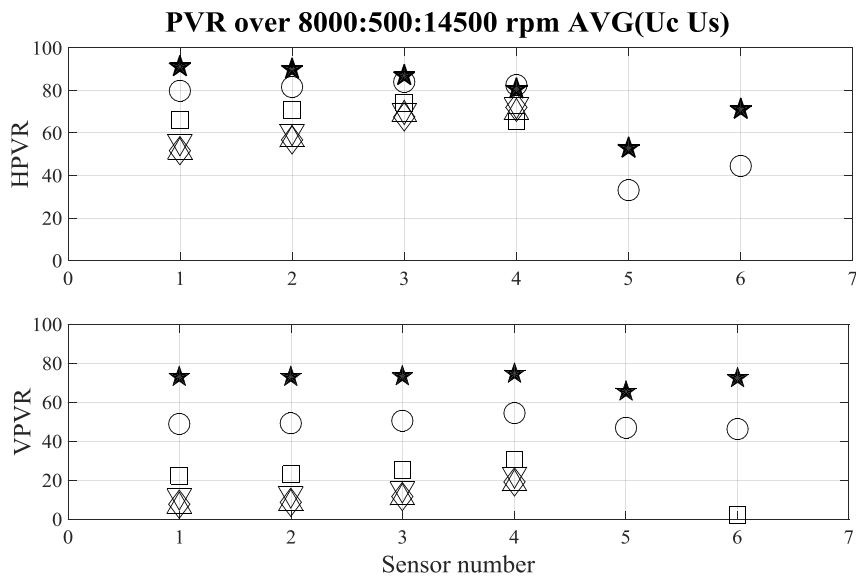

Figure 9: Effect of the conditioning of $\boldsymbol{U}_{\text {aug }}$ on PVRs when the number of measurement speeds $\left(n_{o}\right)$ are increased: $n_{o}=9$ speeds $(\triangle) ; n_{o}=13$ speeds $(\diamond) ; n_{0}=15$ speeds $(\square$ ); $n_{o}=17$ speeds $\left.\left.\quad\right) ; n_{o}=19 \operatorname{speed} \bigcirc \quad\right) ; n_{o}=21 \operatorname{speed} \nabla($ )

\subsection{Noise addition.}

The casing vibration measurements are usually contaminated by noise $[2,8,9]$. This part of the study considers noisy data as practical scenario to test the robustness. Therefore, simulated time histories from the sensors were corrupted with different levels of noise quantified by the signal-to-noise-ratio (SNR): 


$$
S N R=20 \log _{10}\left(\frac{A_{\text {signal }}}{A_{\text {noise }}}\right)
$$

where $A_{\text {signal }}$ is the root-mean-square (RMS) value of the signal without noise and $A_{\text {noise }}$ is the RMS value of the noise. The following results were obtained using data from fixed $n_{s}=6$ locations and $n_{\mathrm{o}}=17$ speeds to construct the inverse operator since this case presented better results over the two previous sections. Figure 10 show the effect of the noise for the current SFD system.
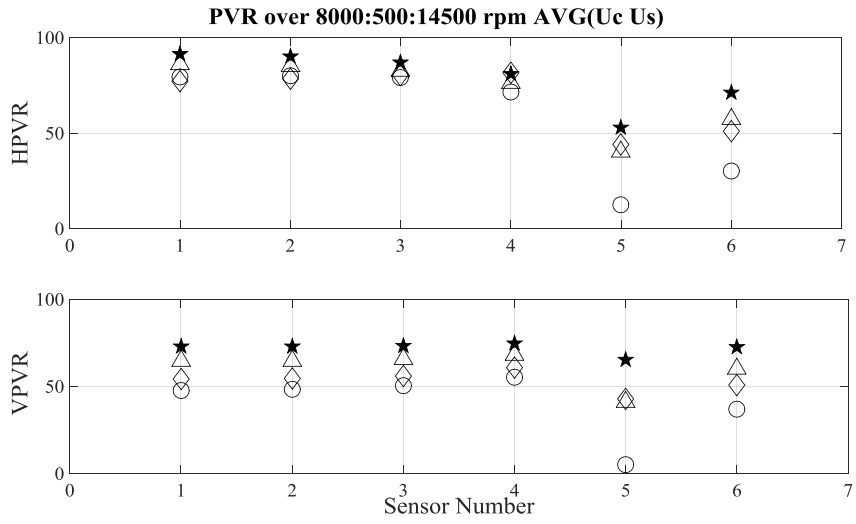

Figure 10: $P V R$ s for different levels of signal-to-noise (SNR) ratio: no noise $(\star) ; S N R=55 \mathrm{~dB}(\triangle) ; S N R=50 \mathrm{~dB}(\diamond)$; $S N R=45 \mathrm{~dB}(\bigcirc)$.

Figure 10 shows that the inverse method is reasonably effective with reasonable levels of noise such as 50 and $55 \mathrm{~dB}$ SNR for which the PVRs are around $60 \%$. It was also noted that the balancing effectives is better for the sensor locations 1-4 rather than 5-6 which are close to the unsupported SFD bearing. A possible explanation for this might be that the influence of the unbalance terms on Equations (19) is weak in comparison to the preceding SFD system reported in $[2,9]$. To illustrate the performance of the balancing method, Figure 11 shows velocity orbits (45dB SNR) at the sensor locations over the casing before and after balancing at $14000 \mathrm{rpm}$. This figure visibly shows the poor effectiveness balancing over 5 and 6 sensor locations.

\section{CONCLUSIONS}

The purpose of the current study was to determine the effectiveness of an inverse technique for balancing when it is applied to a practical aero-engine design in which the HP rotor was supported on the casing by a spring-supported SFD at one end and an unsupported SFD at the other end. This system was considerably different from previously considered systems since it had only one linear connection rotor between the rotor

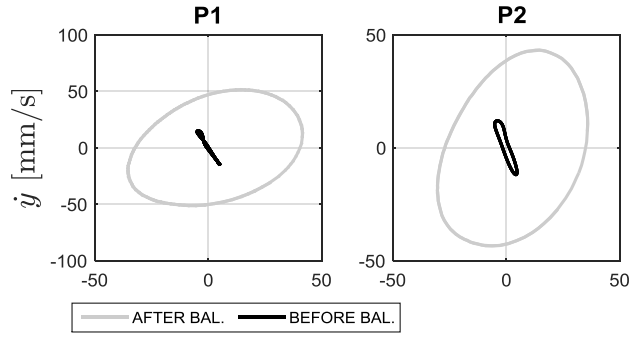

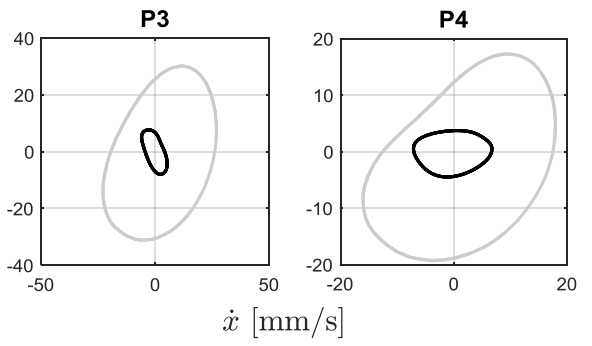

$\mathbf{C}_{\mathbf{p}_{i} \hat{\mathbf{u}}}(\Omega), \mathbf{C}_{\boldsymbol{\theta v}}(\Omega)$,

$\mathbf{C}_{\theta \mathbf{g}}(\Omega), \mathbf{C}_{\theta \widehat{u}}(\Omega)$

$\mathbf{e}_{\mathbf{o}}$

$\mathbf{f}_{\mathrm{b}}$

$\mathbf{f}_{\widehat{\mathbf{u}}}$

$\mathbf{f}_{\mathrm{u}}$

$\mathbf{f}_{\mathrm{v}}$

$\overline{\mathbf{f}_{\mathrm{v}}}, \mathbf{f}_{\mathbf{v}_{\mathbf{c}}}^{(\mathrm{s})}, \mathbf{f}_{\mathbf{v}_{\mathbf{s}}}^{(\mathrm{s})}$

Figure 11: Velocity orbits at casing measurement loca
Amplitude of vibration (half peak-topeak). Eq. 34.

Matrix at one operating speed. Eq. 8

Matrix at one operating speed. Eq. 9

Radial clearance of centred SFD (m)

Receptance matrices evaluated at $\Omega$, section 3.2

vector defining the static offset of $\mathrm{J}$ relative to $B(\mathrm{~m})$

Vector of balancing forces.

Vector of equivalent balance forces.

Vector of unbalance forces.

Vector of SFD forces (N)

Fourier coefficients of SFD forces.
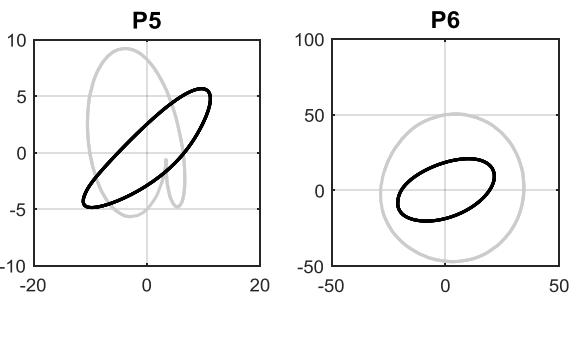


\begin{tabular}{|c|c|}
\hline & \\
\hline $\mathbf{g}$ & Gyroscopic moment vector, Eq. 6 \\
\hline$G$ & $\begin{array}{l}\text { Total number of gyroscopic locations, } \\
\text { Sec. } 3.1\end{array}$ \\
\hline $\mathbf{H}_{\mathrm{b}}, \mathbf{H}_{\mathrm{M}}$ & $\begin{array}{l}\text { Modal matrices whose columns are } \\
\text { respectively the eigenvectors } \\
\text { evaluated in } x, y \text { directions at the }\end{array}$ \\
\hline $\mathbf{H}_{\mathbf{u}}, \mathbf{H}_{\mathrm{g}}$ & locations of the entries \\
\hline $\mathbf{H}_{\mathbf{J}_{n}}, \mathbf{H}_{\mathbf{B}_{n}}$ & $\begin{array}{l}\text { in } \mathbf{f}_{\mathbf{b}}, \mathbf{x}_{\mathbf{p}_{i}}, \mathbf{f}_{\mathbf{u}}, \mathbf{g} \text {. Sec. } 3.1 \\
\text { Modal matrices whose columns are } \\
\text { respectively the eigenvectors } \\
\text { evaluated in } x, y \text { directions at } \\
\text { terminals } \mathrm{J}_{n}, \mathrm{~B}_{n} \text { respectively. Sec. } 3.1\end{array}$ \\
\hline $\mathbf{H}_{\mathbf{v}_{n}}$ & $=\mathbf{H}_{\mathbf{I}_{n}}-\mathbf{H}_{\mathbf{B}_{n}}$, Sec. 3.1 \\
\hline I & Identity matrix \\
\hline$I_{p}$ & $\begin{array}{l}\text { polar moment of inertia at location } p \\
(p=1, \ldots, G) \text {, sec. } 3.1\end{array}$ \\
\hline$n_{o}$ & Number of measurements speeds \\
\hline$n_{s}$ & Number of sensors locations \\
\hline $\mathbf{M}_{\mathbf{p}_{i} \mathbf{v}}(\Omega), \mathbf{M}_{\mathbf{p}_{i} \mathbf{g}}(\Omega)$ & Mobility matrices evaluated at $\Omega$. Sec. \\
\hline $\mathbf{M}_{\mathbf{p}_{i} \widehat{\mathbf{u}}}(\Omega)$ & \\
\hline $\mathrm{P}_{i}$ & Number of sensor location \\
\hline $\mathbf{q}$ & Vector of modal coordinates. \\
\hline$\widehat{\mathbf{u}}_{\mathrm{C}}, \widehat{\mathbf{u}}_{\mathrm{S}}$ & $\begin{array}{l}\text { Coefficients of } \mathbf{f}_{\widehat{\mathbf{u}}} \text { defined in Eqs } \\
(25 \mathrm{a}, \mathrm{b}) \text {. }\end{array}$ \\
\hline $\mathbf{U}(\Omega)$ & Matrix at one operating speed,Eq. (22) \\
\hline $\mathbf{U}_{\text {aug }}$ & $\begin{array}{l}\text { Matrix augmented over a set of } \\
\text { operating speeds, Eq. ( } 24 b)\end{array}$ \\
\hline$U_{k}, \phi_{\mathrm{k}}$ & $\begin{array}{l}\text { Unbalance forces and its angular } \\
\text { position with respect to reference }\end{array}$ \\
\hline & phasor marker at disk no. $k$. \\
\hline$\widehat{U}_{\mathrm{k}}, \hat{\phi}_{\mathrm{k}}$ & $\begin{array}{l}\text { Equivalent unbalance force and its } \\
\text { angular position with respect to } \\
\text { reference phasor marker at balancing } \\
\text { plane no. } k\end{array}$ \\
\hline $\mathbf{w}$ & $\begin{array}{l}\text { Vector of the equivalent static load at } \\
\mathrm{J} \text { in the } x, y \text { directions. }(\mathrm{N})\end{array}$ \\
\hline $\mathbf{x}_{\mathbf{p}}$ & $\begin{array}{l}\text { Vector of displacements at Cartesian } \\
\text { sensor locations. }(\mathrm{m})\end{array}$ \\
\hline$\dot{\mathbf{x}}_{\mathbf{p}}$ & $\begin{array}{l}\text { Vector of velocity readings at } \\
\text { Cartesian sensor locations. }(\mathrm{m} / \mathrm{s})\end{array}$ \\
\hline$\overline{\mathbf{X}}, \mathbf{x}_{\mathbf{p}_{\mathbf{c}}}^{(\mathrm{s})}, \mathbf{x}_{\mathbf{p}_{\mathrm{s}}}^{(\mathrm{s})}$ & $\begin{array}{l}\text { Fourier coefficients of displacements } \\
\text { at Cartesian sensor locations. }\end{array}$ \\
\hline $\mathbf{z}_{\mathbf{p}_{i_{\mathrm{C}}}}^{(s)}, \mathbf{z}_{\mathbf{p}_{i_{S}}}^{(s)}$ & $\begin{array}{l}\text { Fourier coefficients of velocities at } \\
\text { Cartesian sensor locations. }\end{array}$ \\
\hline $\mathbf{z}(\Omega)$ & Vector defined in Eq. 20. \\
\hline $\mathbf{z}_{\text {aug }}$ & $\begin{array}{l}\text { Vector augmented over a set of } \\
\text { operating speeds defined in Eq. } 23\end{array}$ \\
\hline$\gamma$ & $\begin{array}{l}\text { Angle of location of the stationary } \\
\text { phase probe (deg). }\end{array}$ \\
\hline$\kappa$ & Condition Number \\
\hline$\Lambda$ & $\begin{array}{l}\text { The diagonal matrix of squares of } \\
\text { natural frequencies. }\end{array}$ \\
\hline $\boldsymbol{\Psi}_{\mathbf{J}_{n}}^{(r)}, \boldsymbol{\Psi}_{\mathbf{B}_{n}}^{(r)}$ & $\begin{array}{l}\text { Mass-normalized eigenvector defining } \\
\text { the } \mathrm{x} \text { and } \mathrm{y} \text { displacements of the } \\
\text { squeeze-film terminals } \mathrm{J}, \mathrm{B}\end{array}$ \\
\hline
\end{tabular}

respectively in mode no. $r$.

$$
\begin{aligned}
& \boldsymbol{\psi}_{\mathbf{v}_{n}}^{(r)} \quad=\boldsymbol{\Psi}_{\mathbf{J}_{n}}^{(r)}-\boldsymbol{\psi}_{\mathbf{B}_{n}}^{(r)} \\
& \boldsymbol{\Psi}_{\mathbf{u}}^{(r)}, \boldsymbol{\Psi}_{\widehat{\mathbf{u}}}^{(r)}, \\
& \boldsymbol{\Psi}_{\mathbf{g}}^{(r)}, \boldsymbol{\Psi}_{\mathbf{p}_{i}}^{(r)}, \\
& \psi_{\theta}^{(r)} \\
& \Omega \quad \text { Rotational speed ( } \mathrm{rad} / \mathrm{s}) \\
& \begin{array}{ll}
\omega_{r} & \mathrm{~N}
\end{array}
\end{aligned}
$$

\section{REFERENCES}

[1] Dicken, V., Maaß, P., Menz, I., Niebsch, J., Ramlau, R., 2005, "Nonlinear inverse unbalance reconstruction in rotor dynamics", Inverse Probl. Sci. Eng. 13, pp.507-543.

[2] Torres Cedillo, S.G., Bonello, P., 2016, "An equivalent unbalance identification method for the balancing of nonlinear squeeze-film damped rotordynamic systems", J. Sound Vib. 360 pp. 53-73.

[3] Bishop, R.E.D., Gladwell, G.M.L., 1959, "The Vibration and Balancing of an Unbalanced Flexible Rotor", J. Mech. Eng. Sci., 1 (1), pp. 66-77..

[4] Goodman, T.P., 1964, "A least-squares method for computing balance corrections", J. Manuf. Sci. Eng., 86(3), pp. 273-277.

[5] Darlow, M.S., 1987, "Balancing of high-speed machinery: Theory, methods and experimental results", Mech. Syst. Signal Process., 1 (1) pp. 105-134.

[6] Lees, A.W., Friswell, M.I., 1997, "The evaluation of rotor imbalance in flexibly mounted machines", J. Sound Vib., 208 (5) 671-683.

[7] Sinha, J.K., Lees, A.W., Friswell, M.I., 2004, "Estimating unbalance and misalignment of a flexible rotating machine from a single run-down", J. Sound Vib., 272 (3-5), pp. $967-$ 989.

[8] Ramlau, R., Dicken, V., Maaß, P., Streller, C. Rienäcker, A., 2006, "Inverse imbalance reconstruction in rotordynamics", ZAMM - J. Appl. Math. Mech. / Zeitschrift Für Angew. Math. Und Mech., 86 (5), pp. 385-399.

[9] Torres Cedillo, S.G., Bonello, P., 2014, "Unbalance identification and balancing of nonlinear rotodynamic systems", Vol. 7A Struct. Dyn., pp. V07AT31A004.

[10] Bonello, P., Minh Hai, P., 2009, "A receptance harmonic balance technique for the computation of the vibration of a whole aero-engine model with nonlinear bearings", J. Sound Vib. 324 (1-2), pp. 221-242.

[11] Zeidan, F.Y., San Andres, L., Vance, J.M., 1996, "Design and application of squeeze film dampers in rotating machinery", in: Proc. 25th Turbomach. Symp., pp. 169-188.

[12] Dede, M.M., Dogan, M., Holmes, R., 1985, "The damping capacity of a sealed squeeze film bearing", J. Tribol., 107 (3), pp. 411-418.

[13] Hai, P., Bonello, P., 2008, "An impulsive receptance technique for the time domain computation of the vibration of a whole aero-engine model with nonlinear bearings", J. Sound Vib., 318 (3), pp. 592-605.

[14] Bonello, P., Hai, P., 2009, "Computational studies of the unbalance response of a whole aero-engine model with squeeze-film bearings", J. Eng. Gas Turbines Power. 132 (3) :032504-032504-7.

[15] Reymond, M., 2005, "MSC . Nastran realase guide",

[16] Ewins, D.J., 1984, "Modal testing: theory and practice"., ed. E.d.s.M.e.r. 
[17] Vogel, C.R., 2002, "Computational methods for inverse problems", Society for Industrial and Applied Mathematics.

[18] Mathworks Inc, 2011, "Matlab user guide". 